\title{
REGISTER UND VERZEICHNISSE
}

Verzeichnis der Einfügungen, Bemerkungen und Überlegungen von Marx

Verzeichnis der nicht überlieferten Exzerpthefte

Namenregister

Literaturregister

1. Bücher, Artikel und andere nichtperiodische Publikationen

2. Periodica

Verzeichnis der im Apparat ausgewerteten Quellen und der benutzten Literatur

1. Archivalien

2. Gedruckte Quellen

3. Nachschlagewerke und Bibliographien

4. Forschungsliteratur

Sachregister

Verzeichnis der Abbildungen

Notizbuch aus den Jahren 1844-1847. Titelblatt

Notizbuch aus den Jahren 1844-1847. Zweite Seite des Vorsatzes

Notizbuch aus den Jahren 1844-1847. Seite [33]

Notizbuch aus den Jahren 1844-1847. Seite [53]

Exzerpte aus Pierre de Boisguillebert: Le détail de la France.

Seite 1

Exzerpte aus Jean Law: Considérations sur le numéraire ... Seite 21

Brüsseler Hefte 1845. Inhaltsverzeichnis. Heft 1

Exzerpte aus Jean Charles Léonard Simonde de Sismondi:

Études sur l'économie politique. T. 1. Heft 1. Seite XVII

Exzerpte aus Alban de Villeneuve-Bargemont: Économie politique chrétienne. Heft 1. Seite [XIXa]

Brüsseler Hefte 1845. Inhaltsverzeichnis. Heft 2

Exzerpte aus Benjamin Bell: De la disette. Heft 4. Seite [55]

Exzerpte aus Charles Babbage: Traité sur l'économie des machines ... Heft 5. Seite 3 
Exzerpte aus Andrew Ure: Philosophie des manufactures. Heft5.

Text Apparat Seite 11

Exzerpte aus Joseph Pecchio: Histoire de l'économie politique en Italie. Heft 6. Seite 1

Exzerpte aus Joseph Pecchio: Histoire de l'économie politique en Italie. Heft 6 . Seite 7

402

Exzerpte aus John Watts: The facts and fictions of political economists. Heft 6 . Seite 21

431

Berechnungen. Heft 6 . Seite 25

432 
